\title{
AVALIAÇÃO MICROBIOLÓGICA DE SORVETES \\ COMERCIALIZADOS NA CIDADE DE PONTA GROSSA - PR E DA ÁGUA USADA NA LIMPEZA DAS COLHERES UTILIZADAS PARA SERVI-LOS
}

\author{
MICROBIOLOGICAL PROFILE OF ICE-CREAM \\ SOLDS IN MUNICIPALITY OF PONTA GROSSA - PR \\ AND OF THE WATER APPLIED TO CLEAN \\ THE SPOONS USED TO SERVE IT
}

\author{
GRACIANE T. DIOGO ${ }^{1}$ \\ GRAZIELE M. AGUIAR ${ }^{1}$ \\ MARINA C. TOLENTINO ${ }^{1}$ \\ DENISE BUFFARA ${ }^{1}$ \\ MARCOS PILEGGI ${ }^{2}$
}

1 Acadêmica do Curso de Engenharia de Alimentos da UEPG

2 Professor do Departamento de Biologia Estrutural, Molecular e Genética da UEPG

\begin{abstract}
RESUMO
Este trabalho teve como objetivo submeter a análises microbiológicas três amostras de sorvete comercializadas na cidade de Ponta Grossa - PR e, também, a água onde ficam acondicionadas as colheres utilizadas para servir o sorvete. As análises envolvidas neste trabalho foram a quantificação de enterobactérias,
\end{abstract}


contagem de bolores e leveduras, pesquisa de Staphylococcus aureus e Salmonella $\boldsymbol{s p}$. Das seis amostras analisadas, todas apresentaram-se contaminadas por bolores e leveduras, duas por Staphylococcus aureus, quatro por enterobactérias totais e ausência de Salmonella sp nas sub-amostras analisadas. Assim, de acordo com a Legislação Federal do Ministério da Saúde verifica-se que duas das amostras avaliadas estavam em “condições higiênicas insatisfatórias” e duas em “condições higiênico-sanitárias insatisfatórias”.

Palavras-chave: microbiological profile of ice-cream; fungus; leavening; Staphylococcus aureus; Salmonella sp; Enterobacteriacea family

\section{Introdução}

\subsection{Sorvete}

Não existem registros exatos que indiquem a origem dos sorvetes, mas no século IV a.C., Alexandre o Grande, já apreciava as sobremesas geladas. Em suas campanhas, enchia grandes covas com neve, misturandoas com frutas e mel. Porém, foi em 1292 que o explorador Marco Polo trouxe da China para Veneza a primeira receita de sorvete. (NESTLÉ BRASIL LTDA., 2000).

O sorvete é um produto alimentício classificado como gelado comestível. Basicamente é uma mistura de gorduras e proteínas, com ou sem adição de outros ingredientes. Adicionam-se, também, substâncias que tenham sido submetidas ao congelamento. Isto pode ocorrer somente quando há garantias de que o produto será conservado e mantido no estado congelado ou parcialmente congelado, nas etapas de armazenamento, transporte e entrega ao consumidor. (HOFFMANN et al., 1995).

Os microorganismos encontrados no sorvete podem estar relacionados com os ingredientes utilizados, sendo os quais: leite e seus derivados, gorduras e óleos, algumas proteína, açúcares, água potável, ovos e seus derivados; frutas, cacau, mel, nozes, etc. Podem ser também adicionados alguns aditivos como: estabilizantes, espessantes, acidulantes, aromatizantes e corantes. (HOFFMANN et al., 1995).

Através de pesquisas foi provado que a baixa temperatura do sorvete não inibe o crescimento bacteriano. Portanto, os gelados comestíveis ela- 
borados com laticínios e ovos devem ser pasteurizados.

Assim sendo, os microorganismos que mais preocupam quando da sua presença em sorvetes são:

Enterobactérias: Estão presentes no trato intestinal do homem e de outros animais (SIQUEIRA, 1995). Neste grupo, a mais perigosa é a Salmonella $\boldsymbol{s p}$, que pode causar a febre paratifóide e o tifo. Também é preocupante a presença de Escherichia coli, pois sendo mais fácil de ser detectada que a Salmonella sp. funciona como um indicador de contaminação fecal.

Salmonella sp.: Seu reservatório natural é o trato intestinal do homem e outros animais, principalmente em aves. Moscas e baratas são importantes veículos de disseminação das salmonelas.

São bactérias Gram negativo não esporuladas, patogênicas e não fermentadoras de lactose. (ROITMAM, 1998).

Staphylococcus aureus: Podem ser encontrados na cavidade nasal do homem e de alguns animais, bem como na garganta, podendo provocar infecções e, também, na pele. Pode provocar intoxicações alimentares. São bactérias esporuladas, imóveis, produtores de toxinas (algumas cepas) e anaeróbias facultativas. (SIQUEIRA, 1995).

Bolores e leveduras: alguns tipos de fungos produzem microtoxinas que são graves agentes hepatocancerígenos. Normalmente, estas microtoxinas não aparecem diretamente no sorvete, porém podem ser a ele conduzidas através de elementos contidos nas coberturas, principalmente os derivados de cereais. (HOFFMANN et al., 1995).

Assim, para evitar ou controlar a contaminação do sorvete é necessário: selecionar matérias-primas de boa qualidade, utilizar pasteurização ou outro tratamento térmico para reduzir a população microbiana, evitar a contaminação pós-pasteurização e ainda, manter o produto constantemente em baixa temperatura. Em termos de industria também deverá ser prática comum o monitoramento dos chamados pontos críticos de controle para não aumentar a chance da ocorrência de outros contaminantes. (HOFFMANN et al., 1995).

\section{2 Água}

A água serve de veículo para a transmissão de uma variedade de 
doenças causada por microorganismos. Os níveis de contaminação toleráveis para a água são estabelecidos em função do uso pretendido. A Legislação impõe padrões microbiológicos de qualidade para os seguintes tipos de água: potável; destinada a animais que servem de alimento ao homem; destinada a navegação; à recreação e irrigação de plantas; à harmonia paisagista e ao abastecimento industrial. (ROITMAN, 1988).

Assim, como não há padrão específico para o tipo de água que analisou-se, esta foi analisada sob os mesmos padrões do sorvete, já que contém matéria orgânica do mesmo.

Decidiu-se, então, analisar microbiologicamente amostras de sorvetes comercializados na cidade de Ponta Grossa - PR, bem como, a água onde ficam acondicionadas as colheres usadas para servi-lo, pois esta pode servir como um veículo de contaminação do sorvete já que permanece à temperatura ambiente e contém matéria orgânica (leite, açúcar etc), sendo um ótimo substrato para a proliferação de microorganismos.

Dessa forma, foi analisada a presença de Salmonella sp., Staphylococcus aureus, Enterobactérias e bolores e leveduras, pois são os microorganismos mais comumente encontrados em sorvetes.

\section{Materiais e métodos}

\subsection{Amostras}

Analisou-se três amostras de sorvete de creme e três amostras da água onde ficam acondicionadas as colheres utilizadas para pegar massa de sorvete, colhidas em uma sorveteria de pequeno e uma de médio porte, e também em um supermercado que serve em casquinhas o sorvete de uma grande indústria. As amostras foram coletadas em frascos de vidro estéreis e a água foi coletada assepticamente com o auxílio de uma pipeta estéril. Em seguida essas amostras foram acondicionadas em uma bolsa térmica e levadas para o Laboratório de Microbiologia da UEPG, onde foi feita a análise imediata, sendo apresentada na Tabela 1 a composição das amostras de sorvete. 
Tabela 1 - Composição das amostras de sorvete analisadas

\begin{tabular}{cl}
\hline AMOSTRA & INGREDIENTES \\
\hline A & $\begin{array}{l}\text { Leite pasteurizado, açúcar, gordura hidrogenada, estabilizantes, leite em pó, sabor } \\
\text { artificial de creme. }\end{array}$ \\
\hline B & Leite pasteurizado, leite em pó, estabilizantes, açúcar, sabor artificial de creme \\
\hline C & $\begin{array}{l}\text { Água, açúcar, xarope de glicose, leite em pó desnatado, gordura vegetal } \\
\text { hidrogenada, gelatina, açúcar invertido, aromatizantes, corantes artificiais } \\
\text { (amarelo crepúsculo, amarelo trartazina), espessantes, goma guar, goma jataí, } \\
\text { estabilizante monoestearato de glicerina e polisorbato 80. }\end{array}$ \\
\hline
\end{tabular}

\subsection{Preparo das amostras}

Pesou-se assepticamente 10g. de sorvete e diluiu-se em $90 \mathrm{~mL}$ de salina ( $\mathrm{NaCl}$ 0,9\%) preparando, assim, uma diluição $10^{-1}$. A partir desta, obteve-se uma diluição $10^{-2}$.

Pipetou-se assepticamente $1 \mathrm{~mL}$ da água coletada e colocou-se em um tubo de ensaio contendo $9 \mathrm{~mL}$ de salina, preparando-se, assim, uma solução $10^{-1}$. A análise de cada amostra foi feita em duplicata.

\subsection{Contagem de bolores e leveduras}

Pipetou-se assepticamente $0,25 \mathrm{~mL}$ da diluição $10^{-1}$ do sorvete e da água sem diluir e colocou-se em placas de Petri identificadas contendo meio ágar Sabouraud (Tabela 2). Da diluição $10^{-2}$ de sorvete e $10^{-1}$ da água foram pipetados $0,1 \mathrm{~mL}$ e colocados em cada placa. Realizou-se, então, o método de semeadura em superfície. Incubou-se à $28^{\circ} \mathrm{C}$ durante 48 horas. Contouse e calculou-se as médias das unidades formadoras de colônias.

\subsection{Pesquisa de Salmonella sp.}

Pipetou-se assepticamente $0,25 \mathrm{~mL}$ da água sem diluir e da diluição $10^{-1}$ do sorvete e colocou-se em placas de Petri identificadas e contendo meio ágar SS ( Tabela 2). Da diluição $10^{-2}$ do sorvete e $10^{-1} \mathrm{da}$ água pipetouse $0,1 \mathrm{~mL}$ colocando-se em cada placa realizou-se o método da semeadura em superfície. Incubou-se à $37^{\circ} \mathrm{C}$ durante 48 horas. As colônias suspeitas foram analisadas mediante testes bioquímicos. 


\subsection{Pesquisa de Staphylococcus aureus}

Realizou-se o procedimento como anteriormente, porém, o meio utilizado foi o ágar Staphylococcus. Incubou-se a $37^{\circ} \mathrm{C}$ durante 48 horas. Fez-se coloração de Gram para estimar se as colônias formadas eram de Staphylococcus, e com as que possuíam forma de cacho de uva (vistas no microscópio), fez-se o teste com antibiótico Novobiocina para confirmar a presença de Staphylococcus aureus. Contou-se e calculou-se as médias das u.f.c.

\subsection{Contagem de Enterobactérias totais}

Pipetou-se assepticamente $0,1 \mathrm{~mL}$ das diluições $10^{-1}$ e $10^{-2}$ do sorvete, $10^{-1}$ da água e da água sem diluir e colocou-se em placas identificadas contendo ágar Verde Brilhante (Tabela 2). Realizou-se, então, o método de semeadura em superfície. Incubou-se a $37^{\circ} \mathrm{C}$ durante 24 horas. Contou-se e calculou-se as médias das u.f.c.

Tabela 2 - Composição de meios de cultura

\begin{tabular}{|c|c|}
\hline MEIO DE CULTURA & COMPOSIÇÃO APROXIMADA \\
\hline Ágar SS & $\begin{array}{l}\text { Pó “Lab-Lemco” 5,0g; peptona 5,0g; lactose 10,0g; sais biliares 8,5g; } \\
\text { citrato de sódio 10,0g; hiposulfito sódico 8,5g; citrato férrico 1,0g; verde } \\
\text { brilhante } 0,00033 g \text {; vermelho neutro 0,025g; Ágar 15,0g. } \\
\text { pH 7,0 } \pm 0,2 \text {. }\end{array}$ \\
\hline Ágar Verde Brilhante & $\begin{array}{l}\text { Peptona 10,0g; Bacto-Yeast extrato 3,0g; Bacto-lactose } 10,0 \mathrm{~g} \text {; Bacto- } \\
\text { sacarose 10,0g; cloreto de sódio 5,0g; Bacto-Ágar 20,0g; Bacto-Verde } \\
\text { Brilhante 0,0125g; Bacto-vermelho fenol 0,08g. } \\
\text { pH 6,9 } \pm 0,2 \text { à } 25^{\circ} \mathrm{C} \text {. Autoclavou-se por } 15 \text { minutos }\left(121^{\circ} \mathrm{C}\right) \text {. }\end{array}$ \\
\hline Ágar Macconkey & $\begin{array}{l}\text { Peptona de caseína } 17,0 \mathrm{~g} \text {; Peptona de carne } 3,0 \mathrm{~g} \text {; Lactose } 10,0 \mathrm{~g} \text {; sais } \\
\text { biliares } 1,5 \mathrm{~g} \text {; cloreto de sódio } 5,0 \mathrm{~g} \text {; vermelho neutro } 0,03 \mathrm{~g} \text {; cristais } \\
\text { violeta } 0,001 \mathrm{~g} \text {; Ágar-ágar } 15,0 \mathrm{~g} \text {. } \\
\text { pH 7,1 à } 25^{\circ} \mathrm{C} \text {. Autoclavou-se por } 15 \text { minutos }\left(121^{\circ} \mathrm{C}\right) \text {. }\end{array}$ \\
\hline Ágar Sabouraud & $\begin{array}{l}\text { Peptona de carne 5,0g; glucose } 40,0 \mathrm{~g} \text {; peptona de caseína 5,0g; ágar } \\
\text { 15,0g. } \\
\text { pH 7,0 à 25. Autoclavou-se por } 15 \text { minutos }\left(121^{\circ} \mathrm{C}\right) \text {. }\end{array}$ \\
\hline Ágar Staphylococcus & $\begin{array}{l}\text { Extrato de levedura 2,5g; peptona de caseína 10,0g; gelatina 30,0g; } \\
\text { lactose 2,0g; D-manitol 10,0g; cloreto de sódio 75,0g; vermelho neutro } \\
\text { 0,03g; Fosfato dipotássico 5,0g; Àgar } 15,0 \mathrm{~g} \text {. } \\
\mathrm{pH} \pm 7,0 \text {. Autoclavou-se por } 15 \text { minutos }\left(121^{\circ} \mathrm{C}\right) \text {. }\end{array}$ \\
\hline
\end{tabular}




\section{Resultados e discussão}

Os resultados das análises microbiológicas realizadas estão demonstrados na Tabela 3.

Apesar de na legislação federal não haver padrão para bolores e leveduras, foi constatada a presença dos mesmos em todas as amostras. Para Staphylococcus aureus a legislação estabelece neste produto, padrão de no máximo $10^{3}$ u.f.c./g. Apenas a amostra B da água e do sorvete apresentou esta bactéria em quantidades superiores às permitidas. A amostra A (água e sorvete) e C (sorvete) apresentaram-se contaminadas por Staphylococcus $s p$. em baixas quantidades. A presença de Staphylococcus aureus nos alimentos é interpretada, em geral, como indicativo de contaminação a partir da pele, boca e fossas nasais dos manipuladores de alimentos, bem como da limpeza e da sanificação inadequada dos materiais e equipamentos.

Foi utilizado o meio SS para selecionar colônias de Salmonella sp. ou Shigella sp. Porém, neste meio cresceram dois tipos de colônias (fermentadoras e não fermentadoras de lactose). Sabendo-se que a Salmonella $s p$. não é fermentadora de lactose, realizaram-se testes bioquímicos com algumas das colônias suspeitas das amostras A e B. Para essas colônias analisadas o teste indicou ausência de Salmonella sp. Contudo, não podemos afirmar a ausência desta bactéria nas amostras, pois não foram analisadas todas as colônias suspeitas.

Como no meio SS cresceram tanto colônias fermentadoras como não fermentadoras de lactose, podemos afirmar que este meio não é tão seletivo quanto se acreditava. Isto, provavelmente deve-se ao fato de que sua composição é muito semelhante a composição do meio Macconkey que é um meio específico para Enterobactérias (ver Tabela 2).

Também, pode ser observado através da Tabela 3 que, com exceção da amostra $\mathrm{C}$ do sorvete, todas as demais apresentaram-se contaminadas por Enterobactérias, sendo que as amostras A e B (água e sorvete) ultrapassaram o padrão da legislação federal que admite 1000 u.f.c./g de produto.

Portanto, a amostra A é classificada como "produto em condições higiênicas insatisfatórias", e a amostra B como "produto em condições higiênico-sanitárias insatisfatórias”.

Das três amostras de sorvete e da água analisadas, a que apresentou menor contaminação foi a amostra C. As amostras A e B estão praticamente no mesmo nível de contaminação. O alto nível de contaminação dessas 
amostras, pode ter ocorrido porque são de sorveterias artesanais, onde há o maior contato manual com o produto ou, até mesmo, devido à matériaprima utilizada e a presença de poucos produtos químicos, os quais podem inibir o crescimento bacteriano.

A baixa contaminação da amostra $C$, que é um sorvete industrializado, se deve a alguns fatores como, por exemplo, a presença de muitos produtos químicos (conservantes, estabilizantes etc), a utilização do leite em pó que é menos passível de contaminação em vez de leite fluido em sua composição, como mostra a Tabela 1, e também, ao pouco contato manual em sua fabricação.

Com relação a água, a contaminação deve-se provavelmente, a presença de matérias orgânicas (açúcar, leite, gordura etc) que podem ficar incrustadas no recipiente quando não há uma boa higienização do mesmo. Outro fator é que esta água é captada da torneira, podendo já estar contaminada.

Tabela 3 - Representação dos resultados das análises microbiológicas

\begin{tabular}{lccccc}
\hline & AMOSTRAS & $\begin{array}{l}\text { BOLORES E } \\
\text { LEVEDURAS } \\
\text { (U.F.C./g) }\end{array}$ & $\begin{array}{l}\text { STAPHYLOCOCCUS } \\
\text { AUREUS (U.F.C./g) }\end{array}$ & $\begin{array}{l}\text { SALMONELLA } \\
\text { SP. (U.F.C./g) }\end{array}$ & $\begin{array}{l}\text { ENTEROBACTÉRIAS } \\
\text { (U.F.C./g) }\end{array}$ \\
\hline \multirow{2}{*}{ SORVETE } & $\mathrm{A}$ & $375.10^{3}$ & AUSENTE & AUSENTE* & $53,5.10^{3}$ \\
\cline { 2 - 6 } & $\mathrm{B}$ & $135.10^{3}$ & $3.10^{3}$ & AUSENTE* & $34,5.10^{3}$ \\
\hline \multirow{nyyyyy}{*}{ ÁGUA } & $\mathrm{C}$ & $400.10^{3}$ & AUSENTE & AUSENTE* & - \\
\hline \multirow{2}{*}{$\mathrm{A}$} & $150,5.10^{3}$ & AUSENTE & AUSENTE* & $171.10^{3}$ \\
\hline & $\mathrm{B}$ & $16.10^{3}$ & $1,5.10^{3}$ & AUSENTE* & $96,5.10^{3}$ \\
\hline PADRÃO FEDERAL & $\mathrm{C}$ & $118.10^{3}$ & AUSENTE & AUSENTE* & $510.10^{3}$ \\
\hline *Obs: apenas nas sub-amostras analisadas e não na amostra como um todo & & $10^{2} / \mathrm{g}$ \\
\hline
\end{tabular}

\section{Conclusão}

Os resultados deste trabalho mostram que das seis amostras analisadas todas apresentaram-se contaminadas por bolores e leveduras, duas por Staphylococcus aureus (amostra B), quatro por enterobactérias totais e ausência de Salmonella sp em todas as colônias analisadas. 
Assim, verifica-se que as amostras A e B apresentam um alto índice de contaminação em relação a amostra C. Isto provavelmente deve-se ao fato de que as amostras mais contaminadas provém de sorveterias artesanais, onde há um maior contato manual com o produto, a utilização de poucos produtos químicos que podem inibir o crescimento bacteriano, a falta de higienização de equipamentos e utensílios ou, até mesmo, devido à matéria-prima utilizada. Já a amostra C, provém de uma grande indústria a qual adiciona muitos produtos químicos ao sorvete, há pouco contato manual, utilizam-se de leite em pó, que é menos passível de contaminação, em vez de leite fluido e, provavelmente, há um rigoroso controle de qualidade durante o processo se fabricação.

Portanto, de acordo com a Legislação Federal do Ministério da Saúde, verifica-se que duas das amostras estavam em "condições higiênicas insatisfatórias" e duas em "condições higiênico - sanitárias insatisfatórias".

É provável que grande parte das contaminações dos sorvetes estejam relacionadas ao manuseio do produto às operações de fabricação e à matéria-prima utilizada. Com relação a água, a contaminação encontrada pode provir de quatro fontes (água potável, sorvete, recipiente ou manipulador ). Portanto, o ideal seria analisar todas as fontes, a fim de obter-se resultados mais consistentes.

Recebido para publicação em 10/06/2002. Aceito para publicação em 09/09/2002.

\begin{abstract}
This work establishes a microbiological profile of ice-cream solds in municipality of Ponta Grossa-PR. In addition, this presents a microbiological profile of the water applied to clean the spoons used to serve it. The proposed analyses involves the e quantily of the Enterobacteriacea family, count of fungus and leavening, research of Staphylococcus aureus and Salmonella sp. The experimental results evidenced that every analyzed samples showed fungus and leavening, two showed Staphylococcus aureus, four showed Enterobacteriaceas totals e lack of Salmonella sp. in every colonials analyzed. Then, according with Brazilian Federal Laws, two of the analyzed samples indicating a product of "bad hygienic quality",
\end{abstract}


32

and two was product of "bad hygienic-sanitary" quality.

Key words: microbiological profile of ice-cream; fungus; leavening; Staphylococcus aureus; Salmonella sp; Enterobacteriacea family

Endereço para contato: mpileggi@onda.com.br / mpileggi@uepg.br

(42) 220-3126

\section{REFERÊNCIAS}

1 HOFFMAN, Fernando Leite et al. Qualidade higiênico-sanitária de sorvetes comercializados na cidade de São José do Rio Preto (SP) Brasil. BCPPA. Curitiba, v.13, n.2, p.99-108, jul./dez.1995

2 MADRID, A. Vicente, CENZAND, I., VICENTE, J. M. Manual de Indústrias dos Alimentos. Trad.: José A. Cesehin - São Paulo: Varela, 1995. 559p.

3 MONTEIRO, J. A. Microbiologia de Processos e Produtos. Campinas, Fundação Centro Tropical de Pesquisas e Tecnologia, 1978.

4 NASCIMENTO, R. A. et al. Avaliação Microbiológica de Gelados Comestíveis (Picolé), de Indústrias de Pequeno Porte da Cidade de São Luís - MA. Higiene Alimentar, v. 13, n.64, p.58-61, set. 1999.

5 NESTLÉ BRASIL LTDA. Nestlé. Disponível na Internet. http://www.nestle.com.br/ 23 mai, 2000.

6 BRASIL. Portaria n ${ }^{\circ} 001$ de 28 de janeiro de 1987. Aprova padrões microbiológicos para alimentos. Diário Oficial [da República Federativa do Brasil], Brasília, p.2197-2200, 12 fev. 1987.

7 ROITMAN, Isaac et al. Tratado de Microbiologia. São Paulo: Editora Manolo Ltda, 1987. v.1, p.32-35; 89-90; 92-96.

8 SIQUEIRA, Regina Silva de. Manual de Microbiologia de Alimentos. Rio de Janeiro: EMBRAPA-Centro Nacional de Pesquisa de Tecnologia Agroindustrial, 1995. p. 85-116; 119-130. 